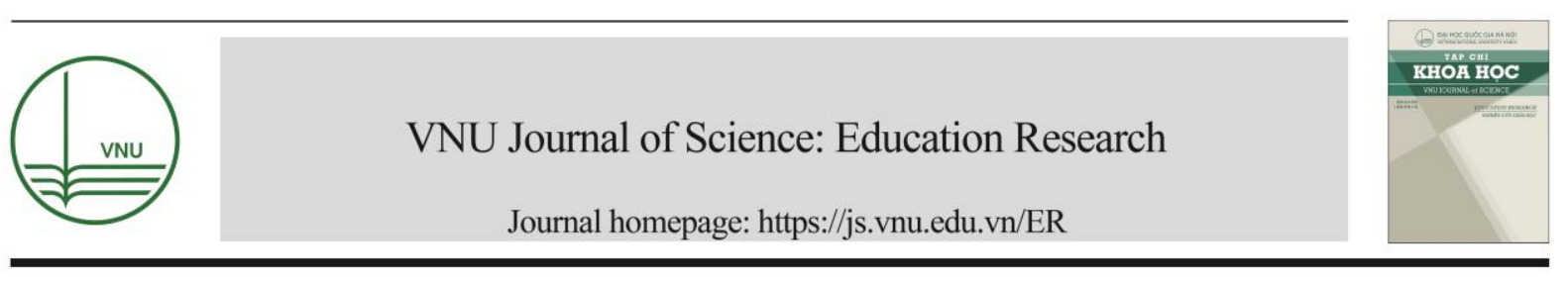

Review Article

\title{
Results of Educational Quality Accreditation and Major Problems of 17 Private Higher Education Instituitions
}

\author{
Dao Thi Hoa ${ }^{1, *}$, Dang Ung Van ${ }^{2}$, Nguyen Thi Le Xuan², Nguyen Thi Thuong ${ }^{2}$ \\ ${ }^{I}$ VNU University of Science, 334 Nguyen Trai, Thanh Xuan, Hanoi, Vietnam \\ ${ }^{2}$ Hoa Binh University, N8 Bui Xuan Phai, My Dinh 2, South Tu Liem, Ha Noi, Vietnam
}

Received 03 April 2019

Revised 15 May 2019; Accepted 14 June 2019

\begin{abstract}
This paper not only outlines the results of external assessment and the accreditation of educational quality of 17 non-state universities according to the Consolidated Document No. 06/2014 / VBHN-BGD DT, implemented by 4 Educational Quality Centers and published the Resolution on social networks, but also proves the foundation of that accreditation's results. With a dataset of 115 samples, we compared with the results of the quality accreditation of 100 public universities and 17 non-public universities proposing the main reasons that the criteria have not been achieved in the non-public universities and some recommendations. Due to the limited framework of the article and the fact that up to now only 17 non-public universities have been assessed base on the old standards (including 10 standards and 61 criteria), we only focus on presenting criteria that more than $20 \%$ of non-state institutions have not met the requirements. (among those 17 non-state universities).
\end{abstract}

Keywords: Higher education institutions, educational quality accreditation.

\footnotetext{
${ }^{*}$ Corresponding author.

E-mail address: daothihoa75@gmail.com

https://doi.org/10.25073/2588-1159/vnuer.4252
} 


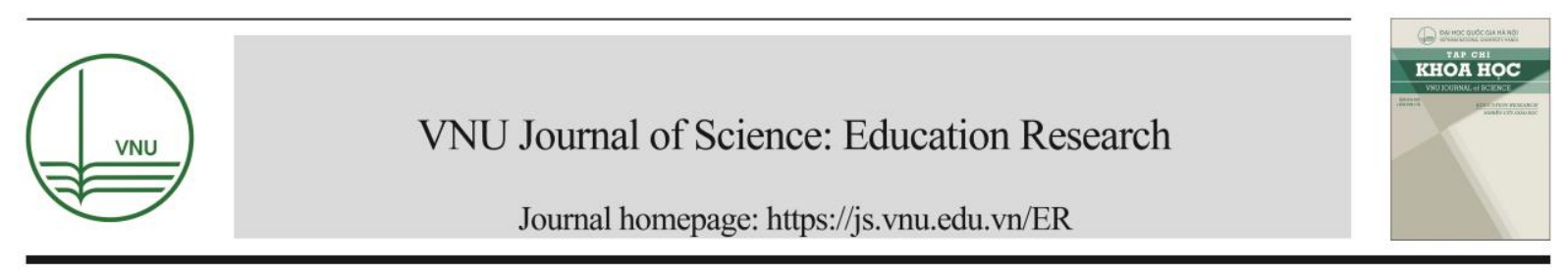

\title{
Kết quả kiểm định chất lượng giáo dục và những tồn tại chủ yếu của 17 cơ sở giáo dục đại học ngoài công lập
}

\author{
Đào Thị Hòa ${ }^{1, *}$, Đặng Ứng Vận ${ }^{2}$, \\ Nguyễn Thị Lệ Xuân², Nguyễn Thị Thương² \\ ${ }^{1}$ Truò̀ng Đại họ Khoa họ Tư nhiên, ĐHQGHN, \\ 334 Nguyễn Trãi, Thanh Xuân, Hà Nội, Việt Nam \\ ${ }^{2}$ Truoòng Đại học Hòa Bình, số 8 Bùi Xuân Phái, Khu đô thị Mỹ Đình 2, \\ Nam Tù Liêm, Hà Nội, Việt Nam \\ Nhận ngày 03 tháng 4 năm 2019 \\ Chỉnh sửa ngày 15 tháng 5 năm 2019; Chấp nhận đăng ngày 14 tháng 6 năm 2019
}

Tóm tắt: Bài viết này không chỉ là báo cáo kết quả đánh giá ngoài và kiểm định chất lượng giáo dục của 17 trường đại học ngoài công lập thực hiện theo Văn bản hợp nhất số 06/2014/VBHNBGDĐT do 4 Trung tâm kiểm định chất lượng giáo dục triển khai và đã công bố Nghị quyết trên các mạng xã hội mà còn chứng minh các luận cứ từ kết quả kiểm định đó. Với tổng số 115 mẫu, nghiên cứu đã tiến hành so sánh, đối chiếu với kết quả kiểm định chất lượng của 100 trường đại học công lập và 17 trường đại học ngoài công lập đề xuất các nguyên nhân chính mà các tiêu chí đã không đạt được ở khối các trường ngoài công lập cùng một số khuyến nghị. Do khuôn khổ hạn chế của bài báo và thực tế cho đến thời điểm này chỉ có tổng 17 trường đại học ngoài công lập đã kiểm định theo bộ tiêu chuần cũ (gồm 10 tiêu chuẩn và 61 tiêu chí), chúng tôi chỉ tập trung trình bày các tiêu chí có trên $20 \%$ số trường ngoài công lập không đạt (trong số 17 trường đó). Ngoài ra, một vài tiêu chí có chỉ số đạt cao hơn khối các trường công lập cũng được phân tích trong nghiên cứu này.

Tù khóa: Cơ sở giáo dục đại học, kiểm định chất lượng giáo dục.

\section{Mô tả chung}

Quá trình đánh giá các cơ sở giáo dục từ tháng 01 năm 2016 đến 31/5/2018, bốn Trung tâm kiểm định chất lượng giáo dục Việt Nam đã đánh giá ngoài 122 trường Đại học trong đó có 117 trường Đại học/Học viện đã được công nhận đạt tiêu chuẩn chất lượng giáo dục, có 05

\footnotetext{
* Tác giả liên hệ.

Địa chi email: daothihoa75@gmail.com

https://doi.org/10.25073/2588-1159/vnuer.4252
}

trường Đại học/Học viện chưa được công nhận. Trong 117 trường Đại học/Học viện được công nhận đạt tiêu chuẩn chất lượng giáo dục, chỉ có 17 trường Đại học ngoài công lập (ngoài công lập-tư thục và dân lập) chiếm $15,4 \%$. Tỷ lệ này xấp xỉ với tỷ lệ chung số các trường đại học ngoài công lập/tổng số các trường đại học của Việt Nam [1-5].

Kết quả kiểm định chất lượng giáo dục công khai trên cổng thông tin điện tử của bốn Trung tâm cho thấy trong 10 tiêu chuẩn với 61 tiêu chí đánh giá chất lượng có 09 tiêu chí $100 \%$ các cơ sở giáo dục đại học đều đạt: Sứ 
mạng của trường đại học; các hoạt động của tổ chức Đảng và các tổ chức đoàn thể; đảm bảo các quyền dân chủ trong trường đại học cho cán bộ, giảng viên; người học được hướng dẫn đầy đủ về chương trình đào tạo, kiểm tra đánh giá và các quy định trong quy chế đào tạo của Bộ Giáo dục và Đào tạo; công tác rèn luyện chính trị, tư tưởng, đạo đức và lối sống cho người học được thực hiện có hiệu quả; công tác Đảng, đoàn thể có tác dụng tốt trong việc rèn luyện chính trị, tư tưởng, đạo đức và lối sống cho người học; thường xuyên tuyên truyền, giáo dục đạo đức, lối sống lành mạnh, tinh thần trách nhiệm, tôn trọng luật pháp, chủ trương, đường lối, chính sách của Đảng và Nhà nước và các nội quy của nhà trường cho người học; có các hoạt động hỗ trợ hiệu quả nhằm tăng tỷ lệ người tốt nghiệp có việc làm phù hợp với ngành nghề đào tạo; các hoạt động hợp tác quốc tế được thực hiện theo quy định của Nhà nước. Với 52 tiêu chí còn lại, mỗi tiêu chí có ít nhất một có sở giáo dục đại học "chưa đạt" [1-5].

Công tác đánh giá và kiểm định chất lượng giáo dục ngoài việc tuân thủ các quy trình công việc và Bộ tiêu chuẩn cùng hướng dẫn đánh giá từng tiêu chí theo Công văn số 1237/KTKĐCLGD-KĐĐH ngày 03/8/2016 của Cục Khảo thí và Kiểm định chất lượng giáo dục (nay là Cục Quản lý chất lượng), đứng trên kết quả đầu ra có thể nhận thấy tính khách quan, công bằng và minh bạch của quá trình đánh giá.

Cả nước có 4 Trung tâm kiểm định chất lượng giáo dục tham gia đánh giá, việc triển khai công tác đánh giá và kiểm định của các Trung tâm được thực hiện vào các thời điểm khác nhau. Trong 117 cơ sở giáo dục đại học được công nhận kết quả, Trung tâm kiểm định chất lượng giáo dục Đại học Quốc Gia Hà Nội (VNU - CEA) đánh giá được 50 cơ sở giáo dục (chiếm 42,7\%),Trung tâm kiểm định chất lượng giáo dục Đại học Quốc gia Thành phố Hồ Chí Minh (VNUHCM - CEA) đánh giá được 24 cơ sở giáo dục (chiếm 20,5\%), Trung tâm kiểm định chất lượng giáo dục thuộc Hiệp hội các Trường Đại học và Cao đẳng Việt Nam (CEA AVU\&C) đánh giá được 34 cơ sở giáo dục (chiếm 29,1\%), Trung tâm kiểm định chất lượng giáo dục đặt tại Đà Nẵng đánh giá được 9 cơ sở giáo dục (chiếm 7,7\%) [5].

So sánh thực trạng kết quả kiểm định chất lượng các cơ sở giáo dục cho thấy có sự chênh lệch khá rõ rệt giữa các trường công lập và ngoài công lập. 12/17 số các trường ngoài công lập được công nhận và kiểm định có tới 11 và 12 tiêu chí chưa đạt trong khi tỷ lệ này ở các trường công là 38/100. 5/17 số trường ngoài công lập còn lại có 9 và 10 tiêu chí không đạt trong khi đó với các trường công là 43/100. Đặc biệt là ở các trường công có tới 19/100 số trường có 8 tiêu chí trở xuống chưa đạt thì các trường ngoài công lập không có trường nào.

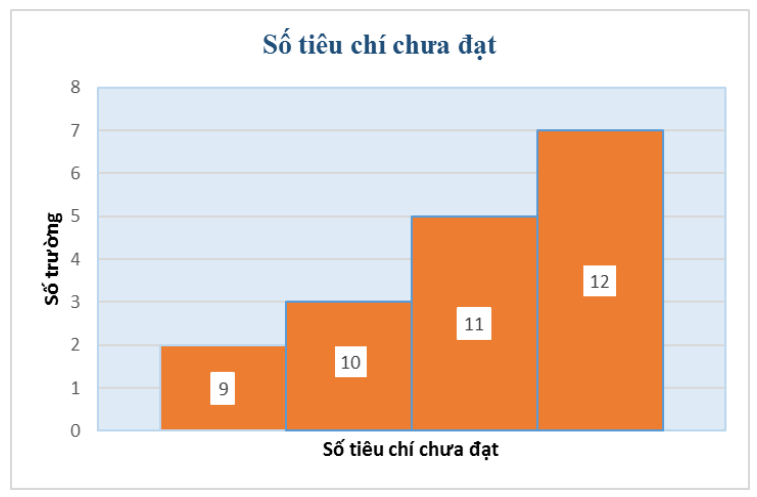

Hình 1. Số tiêu chí chưa đạt của cơ sở giáo dục ngoài công lập.

Điều này minh chứng cho việc triển khai kiểm định chất lượng giáo dục trong thời gian qua đã tương đối khách quan.

Bảng 1. Các tiêu chí chưa đạt giữa trường công lập và ngoài công lập

\begin{tabular}{lll}
\hline Tiêu chí "chưa đạt" & Công lập & Ngoài công lập \\
\hline 5 tiêu chí & $1 / 100$ & $0 / 17$ \\
6 tiêu chí & $1 / 100$ & $0 / 17$ \\
7 tiêu chí & $6 / 100$ & $0 / 17$ \\
8 tiêu chí & $11 / 100$ & $0 / 17$ \\
9 tiêu chí & $20 / 100$ & $2 / 17$ \\
10 tiêu chí & $23 / 100$ & $3 / 18$ \\
11 tiêu chí & $20 / 100$ & $5 / 17$ \\
12 tiêu chí & $18 / 100$ & $7 / 17$ \\
\hline Tổng & 100 & 17 \\
\hline
\end{tabular}


Phân tích về các tiêu chí chưa đạt của khối các trường ngoài công lập cũng củng cố thêm nhận xét này. Từ kết quả đánh giá chất lượng giáo dục, có đến 17 trường ngoài công lập được kiểm định chất lượng giáo dục chưa đạt yêu cầu của tiêu chí 7.5 về "Đảm bảo nguồn thu từ nghiên cứu khoa học và chuyển giao công nghệ không ít hơn kinh phí của trường đại học dành cho các hoạt động này". (Tỷ lệ chung của cả 117 trường là $77.8 \%$ ). Sự cân bằng về trình độ của giảng viên (tiêu chí 5.6); Hoạt động kiểm tra, đánh giá (tiêu chí 4.4); Về diện tích (tiêu chí 9.7); Mục tiêu và chuẩn đầu ra của chương trình đào tạo (tiêu chí 3.2); Lấy ý kiến phản hồi của người học (tiêu chí 6.9); Phân bổ tài chính (tiêu chí 10.3); Xây dựng kế hoạch chiến lược phát triển (tiêu chí 2.6) các trường ngoài công lập có tỉ lệ "chưa đạt" các tiêu chí này cao hơn so với mặt bằng chung và so với các trường công lập. Kết quả đánh như vậy phù hợp với thực tiễn trong giai đoạn vừa qua.

\section{Phân tích những điểm yếu của các cơ sở giáo dục đại học ngoài công lập dựa trên các tiêu chí chưa đạt}

Trong bức tranh chung 61 tiêu chí của 10 tiêu chuẩn phản ánh quản trị đại học theo từng chức năng của một cơ sở giáo dục. Trong tổng số 61 tiêu chí, có 21 tiêu chí mà tất cả các cơ sở giáo dục ngoài công lập đều đạt; các tiêu chí còn lại, mỗi tiêu chí có ít nhất một cơ sở giáo dục chưa đạt. Tiêu chí có nhiều cơ sở giáo dục chưa đạt nhất (100\%) là tiêu chí 7.5.

Sau đây báo cáo sẽ phân tích 21 tiêu chí, mỗi tiêu chí có ít nhất $3 / 17$ các cơ sở giáo dục ngoài công lập chưa đạt. Các tiêu chí còn lại có dưới $2 / 17$ cơ sở giáo dục chưa đạt và tất cả các tiêu chí của Tiêu chuẩn 1 đều có không có cơ sở giáo dục ngoài công lập nào chưa đạt sẽ không đưa vào phân tích.

\subsection{Tiêu chuẩn 2: Tổ chức và Quản lý}

Tiêu chuẩn 2 có 7 tiêu chí đánh giá về mặt tổ chức và quản lý của cơ sở giáo dục. Trong đó có hai tiêu chí (tiêu chí 2.2 và tiêu chí 2.6) có tỷ lệ các cơ sở giáo dục chưa đạt là $5 / 17$ và $8 / 17$.

Tiêu chí 2.1: Cơ cấu tổ chức của trường đại học được thực hiện theo quy định của Điểu lệ trường đại học và các quy định pháp luật khác có liên quan, được cụ thể hóa trong quy chế về tổ chức và hoạt động của nhà trường.

Chỉ có $2 / 17$ cơ sở giáo dục được đánh giá chưa có có cấu tổ chức đáp ứng các quy định của Điều lệ trường Đại học và các quy định khác của pháp luật có liên quan (chưa thành lập Hội đồng khoa học và một số tổ chức khác đúng quy định, một số trường chưa cập nhật và xây dựng quy chế về tổ chức và hoạt động theo đúng quy định hiện hành, v.v...). Các lý do cụ thể dẫn tới thực trạng này là:

- Thành viên của Hội đồng quản trị chưa phù hợp theo quy định.

Tiêu chí 2.2. Có hệ thống văn bản để tổ chức, quản lý một cách có hiệu quả các hoạt động của nhà trường.

Có tới $5 / 17$ cơ sở giáo dục ngoài công lập chưa có hoặc có quy chế tổ chức hoạt động nhưng chưa được cập nhật (có cơ sở giáo dục mà quy chế tổ chức được biên soạn từ năm 2008). Nhiều cơ sở giáo dục có cơ cấu tổ chức tại thời điểm đánh giá khác với quy chế tổ chức hiện hành; chưa quy định chức năng nhiệm vụ của các đơn vị thuộc cơ sở giáo dục và mối quan hệ của các đơn vị này.

Một số cơ sở giáo dục có nhiều đầu mối (đơn vị tương đương phòng) thực hiện cùng một chức năng cho một đối tượng. cơ sở giáo dục chưa xây dựng cơ chế phối hợp chặt chẽ giữa các đầu mối, nên về tổng thể cơ sở giáo dục quản lý chưa tốt đối tượng này.

Tiêu chí 2.6: Có chiến lược và kế hoạch phát triển ngắn hạn, trung hạn, dài hạn phù hợp với định hướng phát triển và sứ mạng của nhà trường; có chính sách và biện pháp giám sát, đánh giá việc thực hiện các kế hoạch của nhà trường.

Lý do chủ yếu làm cho 7/17 số cơ sở giáo dục không đạt tiêu chí này:

- Chưa có chiến lược và kế hoạch phát triển trong dài hạn. Nhiều cơ sở giáo dục sử dụng Đề 
án khả thi mở trường, coi đó là chiến lược phát triển dài hạn.

Nhiều cơ sở giáo dục có chiến lược và kế hoạch phát triển trong 5 năm, nhưng không có kế hoạch trung hạn và hàng năm nhằm đạt được kế hoạch 5 năm.

- Các kế hoạch phát triển trong dài hạn, trung hạn, hàng năm chưa có các kế hoạch về các hoạt động như đào tạo, nghiên cứu khoa học... cùng kế hoạch về các nguồn lực đảm bảo cho các kế hoạch, các hoạt động này.

- Trong quá trình thực hiện, cơ sở giáo dục chưa xây dựng được hệ thống chỉ tiêu (KPI) và định kỳ đánh giá, giám sát nhằm thực hiện đúng kế hoạch và điều chỉnh cho phù hợp với thực tế.

\subsection{Tiêu chuẩn 3: Chuoong trình đào tạo.}

Tiêu chuẩn này đánh giá quản trị của cơ sỏ giáo dục về 6 nội dung từ xây dựng chương trình đào tạo, chuẩn đầu ra, kết cấu chương trình đào tạo, đổi mới chương trình đào tạo, và đánh giá chương trình đào tạo. Tiêu chuẩn 3 là tiêu chuẩn mà không có cơ sở giáo dục nào đạt tất cả các tiêu chí. Tiêu chí 3.2 , Tiêu chí 3.4 và Tiêu chí 3.6 có con số các cơ sở giáo dục chưa đạt là $11 / 17,5 / 17$ và $10 / 17$.

Tiêu chí 3.2: Chương trình đào tạo có mục tiêu đào tạo rõ ràng, cụ thể, có kết cấu hợp lý, được thiết kế một cách hệ thống đáp ứng yêu cầu về chuẩn kiến thức, kỹ năng của đào tạo trình độ đại học và đáp ứng linh hoạt nhu cầu của thị trường lao động. Trong tổng số 100 cơ sở giáo dục công lập được công nhận kết quả, số tiêu chí chưa đạt 39 , trong khi số trường ngoài công lập chưa đạt tiêu chí này là $11 / 17$ dẫn đến chênh lệch giữa cơ sở giáo dục ngoài công lập so với công lập là khá cao. Để đạt được Tiêu chí này đòi hỏi các cơ sở giáo dục đạt được 5 mốc chuẩn. Nguyên nhân không đạt thường là:

- Chuẩn đầu ra còn phân biệt giữa các hình thức đào tạo (hình thức đào tạo chính quy, đào tạo vừa làm vừa học), chưa liên kết giữa mục tiêu đào tạo với chuẩn đầu ra và chương trình đào tạo, chưa đảm bảo được việc đo lường và đánh giá, chưa được công khai hóa. Chuẩn đầu ra còn được soạn thảo với tư cách là bên cung kiến thức mà chưa đứng trên phía người học cần phải đạt được. Chuẩn đầu ra về ngoại ngữ còn thấp hơn so với yêu cầu của Bộ GD\&ĐT.

- Chương trình đào tạo: cơ sở giáo dục chưa cụ thể hóa văn bản về kết cấu chương trình đào tạo dẫn đến các chương trình đào tạo có kết cấu rất khác nhau (mục tiêu đào tạo, chuẩn đầu ra, tỷ lệ các khối kiến thức, tỷ lệ các học phần tự chọn...). chương trình đào tạo cho hình thức vừa làm vừa học khác biệt nhiều với hình thức đào tạo chính quy (học phần, cách đánh giá học phần, tổ chức đào tạo).

- Tham khảo các chương trình đào tạo tiên tiến trong và ngoài nước còn rất hạn chế. Nếu có tham khảo mới dừng lại ở việc xem xét các chương trình đào tạo tham khảo có những học phần gì, việc đối chiếu so sánh, bám sát mục tiêu đào tạo ít được đề cập. Minh chứng cho tham khảo chương trình đào tạo ở nhiều cơ sở giáo dục chỉ là các đường dẫn trên internet. chương trình đào tạo chưa được công khai hóa.

- Hệ thống đề cương học phần: cơ sở giáo dục chưa cụ thể hóa văn bản về đề cương chi tiết học phần, nên một số yếu tố cấu thành của đề cương không có (thẩm quyền phê duyệt đề cương, phân bổ thời gian cho lý thuyết và thực hành, hình thức kiểm tra đánh giá, tài liệu tham khảo...). Hệ thống đề cương chưa được công khai hóa; người học chưa được phổ biến đề cương một cách đầy đủ và rõ ràng, nhất là đối với người học theo hình thức vừa làm vừa học, người học sau đại học. Giáo trình và tài liệu tham khảo chưa đầy đủ...

- Việc tham khảo ý kiến của các bên liên quan để cây dựng chương trình đào tạo và chuẩn đầu ra: yêu cầu này phần lớn các cơ sở giáo dục thực hiện chưa tốt. Các cơ sở giáo dục dựa trên kinh nghiệm để xây dựng chương trình đào tạo; việc tham khảo bài bản tìm ra chuẩn về kiến thức, về kỹ năng của người học cần phải có khi hoàn thành chương trình đào tạo để thiết kế các học phần, nội dung của học phần chưa được chú ý. Vấn đề đào tạo đáp ứng yêu cầu của thị trường lao động chưa được xem trọng.

Tiêu chí 3.4: Chương trình đào tạo được định kỳ bổ sung, điều chỉnh dựa trên cơ sở tham khảo các chương trình tiên tiến quốc tế và tham khảo ý kiến của các bên liên quan. $5 / 7$ số cơ sở 
giáo dục ngoài công lập chưa đạt tiêu chí này. Các nguyên chủ yếu là:

- Không tham khảo hoặc tham khảo rất ít các chương trình đào tạo tiên tiến trong và ngoài nước. Nếu có tham khảo thì mới chỉ tham khảo về học phần, không có phân tích đối chiếu, so sánh các chương trình đào tạo của cơ sở với các chương trình đào tạo khác.

- Việc lấy ý kiến của các bên liên quan (Nhà tuyển dụng lao động, các Hiệp hội xã hội nghề nghiệp, người học đã tốt nghiệp) rất hạn chế. Thông tin từ việc thu thập ý kiến nhiều trường hợp không có tính đại diện do số người/tổ chức được hỏi ý kiến quá ít. Việc khảo sát để rút ra đề xuất gì về xây dựng, đổi mới chương trình đào tạo còn rất hạn chế, mới dừng ở con số thống kế, nhận xét dựa trên kết quả khảo sát. Việc khảo sát các đối tượng liên quan chưa thực hiện theo ngành.

- Cơ sở giáo dục thiết kế bảng hỏi, thiết kế nội dung phỏng vấn thiếu tính chuyên nghiệp, chưa phù hợp với từng đối tượng khảo sát; không có phần mềm phân tích thống kê cùng cán bộ xử lý kết quả phân tích.

Tiêu chí 3.6: Chương trình đào tạo được định kỳ đánh giá và thực hiện cải tiến chất lượng dựa trên kết quả đánh giá. Để đạt được tiêu chí này, các cơ sở giáo dục cần phải vượt qua 3 yêu cầu: trong năm năm ít nhất một lần đánh giá chương trình đào tạo (tự đánh giá/đánh giá đồng cấp/kiểm định chương trình đào tạo); cơ sở giáo dục có giải pháp cải tiến chất lượng dựa trên kết quả đánh giá và cơ sở giáo dục có biện pháp và thực hiện cải tiến chất lượng chương trình đào tạo dựa trên ý kiến của các bên liên quan. Có tới 10/17 cơ sở giáo dục ngoài công lập chưa đạt tiêu chí này. Lý do chủ yếu không đạt là cơ sở giáo dục không thực hiện định kỳ đánh giá chương trình đào tạo bằng cách tự đánh giá hoặc đánh giá đồng cấp hoặc kiểm định. Rất nhiều cơ sở giáo dục (công và tư) chưa biết được việc đánh giá chương trình đào tạo là đánh giá theo bộ tiêu chuẩn do Bộ GD\&ĐT ban hành hoặc kiểm định chương trình đào tạo do nước ngoài thực hiện.

\subsection{Tiêu chuẩn 4: Hoạt động đào tạo}

Tiêu chuẩn này đánh giá quản trị của cơ sở giáo dục về hoạt động đào tạo. Tiêu chuẩn yêu cầu cơ sở giáo dục phải đa dạng hóa các hình thức đào tạo, tổ chức đào tạo theo tín chỉ, có phương pháp hợp lý đánh giá họat động giảng dạy của giảng viên; đánh giá kết quả học tập của người học khách quan, công bằng, chính xác; đánh giá chất lượng đào tạo đối với người học sau khi ra trường...

Trong 7 tiêu chí, có $1 / 17$ cơ sở giáo dục chưa đạt $3 / 7$ tiêu chí, $5 / 17$ cơ sở giáo dục chưa đạt $2 / 7$ tiêu chí và $10 / 17$ cơ sở giáo dục còn $1 / 7$ tiêu chí chưa đạt.

Tiêu chí 4.3: Có kế hoạch và phương pháp đánh giá hợp lý hoạt động giảng dạy của giảng viên; chú trọng việc triển khai đổi mới phương pháp dạy và học, phương pháp đánh giá kết quả học tập của người học theo hướng phát triển năng lực tự học, tự nghiên cứu và làm việc theo nhóm. Tiêu chí này có $4 / 17$ trường không đạt, với lý do chủ yếu là các trường ngoài công lập còn hạn chế trong việc đổi mới phương pháp dạy học một phần do đội ngũ giảng viên thỉnh giảng được tuyển từ nhiều nguồn khác nhau. Phần nữa là Nhà trường còn chưa chú trọng đến việc đánh giá năng lực mà chủ yếu vẫn duy trì các giải pháp truyền thống.

Tiêu chí 4.4: Phương pháp và quy trình kiểm tra đánh giá được đa dạng hoá, đảm bảo nghiêm túc, khách quan, chính xác, công bằng và phù hợp với hình thức đào tạo, hình thức học tập, mục tiêu môn học và đảm bảo mặt bằng chất lượng giữa các hình thức đào tạo; đánh giá được mức độ tích lũy của người học về kiến thức chuyên môn, kỹ năng thực hành và năng lực phát hiện, giải quyết vấn đề. Tiêu chí này có 3 mốc để đánh giá tiêu chí đạt hay chưa đạt. Có tới 11/17 cơ sở giáo dục ngoài công lập với các lý do chủ yếu:

- Cơ sở giáo dục chưa có quy định về xây dựng, quản lý và sử dụng ngân hàng câu hỏi thi. Công tác làm đề thi còn chưa được quản lý chặt chẽ, có không ít học phần của cơ sở giáo dục giảng viên tự ra đề thi. Đáp án chưa nộp cùng đề thi. Công tác tổ chức thi, quản lý chấm thi còn do nhiều đầu mối thực hiện. 
- Công tác giám sát chấm thi và hậu kiểm hầu như chưa được thực hiện, số lượng bài phúc khảo nhiều (có cơ sở giáo dục tỷ lệ thay đổi điểm thi đối với các trường hợp phúc khảo khá cao, dao động từ $42,4 \%$ đến $49,6 \%$ ).

- Việc xây dựng câu hỏi thi và ngân hàng câu hỏi chưa vận dụng khoa học đo lường trong giáo dục nên chất lượng câu hỏi chưa tốt, phổ điểm kết quả học tập bị lệch.

Tiêu chí 4.7: Về đánh giá chất lượng đào tạo đối với người học sau khi ra trường và kế hoạch điều chỉnh hoạt động đào tạo cho phù hợp với yêu cầu của xã hội. Để đạt được tiêu chí này, cơ sở giáo dục thực hiện đầy đủ 3 yêu cầu: thực hiện đánh giá chất lượng người học sau khi ra trường hằng năm thông qua ý kiến phản hồi của người học đã tốt nghiệp và của đơn vị sử dụng lao động; triển khai điều chỉnh hoạt động đào tạo dựa trên các thông tin phản hồi và lấy ý kiến phản hồi của nhà sử dụng lao động đối với sinh viên tốt nghiệp phải được thực hiện theo ngành có người học tốt nghiệp. Ở tiêu chí này, các cơ sở giáo dục ngoài công lập chỉ có 3/17 cơ sở giáo dục chưa đạt tiêu chí này. Điều này cho thấy các cơ sở giáo dục ngoài công lập rất quan tâm đến quá trình đánh giá chất lượng đào tạo đối với người học sau khi ra trường. Việc khảo sát được thực hiện trên quy mô rộng, thực hiện theo ngành và phương thức khảo sát cũng khoa học và linh hoạt. Chú trọng đến việc xây dựng cơ sở dữ liệu, phân tích dữ liệu để phục vụ mục tiêu dài lâu.

\subsection{Tiêu chuẩn 5: Đội ngũ cán bộ quản lý, giảng viên và nhân viên}

Tiêu chẩn này đánh giá quản trị của cơ sở giáo dục về xây dựng và phát triển đội ngũ cán bộ quản lý, giảng viên và nhân viên đáp ứng nhiệm vụ của cơ sở giáo dục, phù hợp với sứ mạng tầm nhìn của cơ sở giáo dục. Tiêu chuẩn này có 8 tiêu chí, trong đó có 3 tiêu chí tất cả các cơ sở giáo dục đều đạt, 1 tiêu chí $1 / 17$ cơ sở giáo dục chưa đạt. Các tiêu chí còn lại có từ 4 - 13/17 chưa đạt.

Tiêu chí 5.4: Tiêu chí đòi hỏi cơ sở giáo dục có đội ngũ cán bộ quản lý có phẩm chất đạo đức, năng lực quản lý chuyên môn, nghiệp vụ và hoàn thành nhiệm vụ được giao. 6/17cơ sở giáo dục chưa đạt tiêu chí này với các lý do chủ yếu:

- Một số cán bộ quản lý của cơ sở giáo dục không đủ tiêu chuẩn về trình độ theo quy định để đảm nhiệm công tác quản lý (trưởng khoa, trưởng bộ môn có đào tạo ngành/chuyên ngành, trưởng phòng Quản lý đào tạo, trưởng phòng Quản lý khoa học phải có trình độ tiến sĩ).

- Việc đánh giá đội ngũ cán bộ quản lý chỉ được thực hiện vào cuối năm học, đánh giá thi đua khen thưởng. Các cơ sở giáo dục chưa xây dựng được hệ chỉ số (KPI) đánh giá cán bộ quản lý.

Tiêu chí 5.5: Đánh giá về lực lượng cán bộ giảng dạy có đáp ứng được yêu cầu về đào tạo và nghiên cứu khoa học hay không? Để đạt được tiêu chí này cơ sở giáo dục phải có đủ giảng viên cơ hữu và tỷ lệ sinh viên/giảng viên đáp ứng yêu cầu của điều kiện đảm bảo chất lượng và giảm dần qua các năm. $7 / 17$ số cơ sở giáo dục chưa đạt tiêu chí này. Các lý do chủ yếu như sau:

- Lực lượng cán bộ giảng dạy còn thiếu về số lượng, có cơ sở giáo dục tỷ lệ giảng viên cơ hữu chỉ có $22,6 \%$, số lượng giờ giảng vượt định mức trên một giáo viên rất lớn.

- Có những cơ sở giáo dục phân công cán bộ giảng dạy có trình độ cử nhân đại học giảng dạy lý thuyết.

- Tỷ lệ sinh viên/giảng viên quy đổi vượt quá quy định.

Tiêu chí 5.6: Đội ngũ giảng viên đảm bảo trình độ chuẩn được đào tạo; giảng dạy theo chuyên môn được đào tạo; đảm bảo cơ cấu chuyên môn và trình độ theo quy định; có trình độ ngoại ngữ, tin học đáp ứng yêu cầu về nhiệm vụ đào tạo, nghiên cứu khoa học. Tiêu chí 5.6 đòi hỏi cơ sở giáo dục phải đạt được 4 mốc chuẩn về: trình độ của giảng viên, giảng dạy theo chuyên môn được đào tạo, cơ cấu của đội ngũ giảng viên phù hợp với nhiệm vụ và giảng viên có trình độ ngoại ngữ và tin học theo quy định. Có tới 13/17 cơ sở giáo dục chưa đạt được tiêu chí này. Các lý do chủ yếu bao gồm: 
- Cơ sở giáo dục còn có nhiều giảng viên có trình độ đại học tham gia giảng dạy.

- Còn có nhiều giảng viên chưa có chứng chỉ về tin học và ngoại ngữ, chứng chỉ nghiệp vụ sư phạm (đối với giảng viên không tốt nghiệp ngành sư phạm).

Tiêu chí 5.7: Tiêu chí đánh giá về đảm bảo cân bằng giữa kinh nghiệm công tác và trẻ hóa đội ngũ giảng viên. Tiêu chí yêu cầu đội ngũ cán bộ giảng dạy của cơ sở giáo dục có cơ cấu hợp lý về thâm niên công tác để đảm bảo giảng dạy, nghiên cứu khoa học; có độ tuổi trung bình giảm dần. $3 / 17$ số cơ sở giáo dục ngoài công lập chưa đạt tiêu chí này do: Đội ngũ giảng viên cơ hữu chưa cân đối về kinh nghiệm công tác, tỷ lệ giảng viên có thâm niên dưới 10 năm chiếm $40 \%-75 \%$.

\subsection{Tiêu chuẩn 6: Người học}

Tiêu chuẩn 6 đánh giá quyền của người học về tất cả các mặt trong thời gian học tập tại cơ sở giáo dục, bao gồm quyền được hướng dẫn đầy đủ về chương trình đào tạo, về cách đánh giá kết quả học tập, quyền được hưởng các chế độ chính sách, quyền được rèn luyện, phấn đấu toàn diện về văn hóa, thể thao, quyền được nhận xét về hoạt động giảng dạy của giảng viên...Hầu hết các cơ sở giáo dục đều đạt các tiêu chí của Tiêu chuẩn này. Riêng Tiêu chí 6.9 - người học được tham gia đánh giá chất lượng giảng dạy của giảng viên khi kết thúc học phần và đánh giá chất lượng đào tạo trước khi tốt nghiệp - có 6/17 cơ sở giáo dục chưa đạt tiêu chí này. Lý do chủ yếu:

- Cơ sở giáo dục chưa khảo sát ý kiến người học ở tất cả các lớp học phần, tất cả các kỳ học, tất cả các hình thức đào tạo và các bậc đào tạo.

- Phiếu khảo sát chưa bao quát hết các hoạt động giảng dạy của giảng viên, thang đo không phù hợp (3 hay 4 bậc).

- Kết quả khảo sát chưa chuyển tải đến giảng viên, lãnh đạo các cấp có liên quan, chưa theo dõi được quá trình cải tiến của giảng viên qua các năm; các trường hợp có kết quả đánh giá thấp chưa được chú ý giúp đỡ.
2.6. Tiêu chuẩn 7: Nghiên cúu khoa học, ưng dung, phát triển và chuyển giao công nghệ

Tiêu chuẩn này đánh giá về quản trị và kết quả về nghiên cứu khoa học, ứng dụng, phát triển và chuyển giao công nghệ gắn với sứ mạng, tầm nhìn của cơ sở giáo dục. Tiêu chuẩn bao gồm: xây dựng kế hoạch, triển khai thực hiện, đánh giá kết quả; đóng góp về mặt học thuật (các bài báo đăng trên tạp chí khoa học chuyên ngành, tạp chí quốc tế), đóng góp về mặt thực tiễn (chuyển giao công nghệ, ứng dụng thực tiễn); tác dụng của nghiên cứu đối với cơ sở giáo dục về mặt đào tạo, về tài chính...Trong 7 tiêu chí, Tiêu chí $7.2(5 / 17)$ và Tiêu chí 7.5 (17/17) có tỷ lệ cao các cơ sở giáo dục chưa đạt yêu cầu; tiêu chí 7.3 và 7.6 có tỉ lệ chưa đạt là như nhau (2/17); tiêu chí 7.4 và 7.7 có tỷ lệ chưa đạt thấp (chỉ có $1 / 17$ trường) và có 1 tiêu chí 7.1 tỉ lệ chưa đạt 3/17.

Tiêu chí 7.2: Các đề tài, dự án được thực hiện và nghiệm thu theo kế hoạch. $5 / 17$ cơ sở giáo dục ngoài công lập không đạt tiêu chí này, bởi những nguyên nhân chủ yếu là:

- Số đề tài cấp Bộ, cấp Nhà nước của các cơ sở giáo dục ngoài công lập rất ít, chủ yếu là các đề tài cấp trường, kinh phí ít và thời gian thực hiện ngắn.

- Tỷ lệ đề tài nghiên cứu khoa học/giảng viên quá thấp.

Tiêu chí 7.5: Tiêu chí này yêu cầu cơ sở giáo dục phải đảm bảo nguồn thu từ nghiên cứu khoa học và chuyển giao công nghệ không ít hơn kinh phí dành cho các hoạt động nghiên cứu khoa học và chuyển giao công nghệ. 17/17 cơ sở giáo dục ngoài công lập không đạt tiêu chí này và là tiêu chí có tỷ lệ cơ sở giáo dục chưa đạt nhiều nhất trong 61 tiêu chí. Lý do chủ yếu là:

- Cơ sở giáo dục chưa trích đủ kinh phí từ nguồn thu hợp pháp của chính sách cho nghiên cứu khoa học và chuyển giao công nghệ mà dành cho các mục chi khác.

- Cơ sở giáo dục chưa trích đủ kinh phí từ học phí cho nghiên cứu khoa học của sinh viên.

- Không cân đối được chi và thu từ nghiên cứu khoa học và chuyển giao công nghệ $[6,7]$. 


\subsection{Tiêu chuẩn 8: Hoạt động hợp tác quốc tế}

Tiêu chuẩn này yêu cầu hoạt động hợp tác quốc tế cần được thực hiện theo quy định của Nhà nước, có hiệu quả thể hiện qua các chương trình hợp tác đào tạo, trao đổi học thuật, trao đổi giảng viên và người học, các hoạt động tham quan khảo sát, hỗ trợ nâng cấp cơ sở vật chất, trang thiết bị ... các dự án, đề án nghiên cứu khoa học, phát triển công nghệ, các chương trình áp dụng kết quả nghiên cứu khoa học và công nghệ vào thực tiễn, tổ chức các hội nghị, hội thảo khoa học chung, công bố các công trình khoa học chung.

Có tới 8/17 cơ sở giáo dục ngoài công lập không đạt tiêu chí 8.3 do không được sự hỗ trợ từ Nhà nước về hợp tác quốc tế, mặt khác do những hạn chế trong hoạt động khoa học-công nghệ mà nhiều trường ngoài công lập đã không đạt tiêu chí này $[8,9]$. Nếu phân tích kỹ có thể thấy hầu hết các chương trình hợp tác quốc tế về khoa học-công nghệ có hiệu quả của các trường đại học đều là những dự án do Nhà nước hỗ trợ (ngay cả các dự án từ vốn vay $\mathrm{ADB}$ hoặc WTO). Những dự án tư nhân thực là hiếm.

3.9. Tiêu chuẩn 9 Thư viện, trang thiết bị học tập và cơ sở vật chất khác

Tiêu chuẩn này đánh giá cơ sở vật chất phục vụ giảng dạy, nghiên cứu khoa học, học tập của sinh viên. Tiêu chuẩn có 9 tiêu chí, trong đó 3 tiêu chí có 6 - 13/17 cơ sở giáo dục chưa đạt. Tất cả các cơ sở giáo dục đều đạt Tiêu chí 9.4 về thiết bị tin học, tiêu chí 9.9 về các biện pháp bảo vệ tài sản, trật tự an toàn cho cán bộ quản lý, giảng viên, nhân viên và người học.

Tiêu chí 9.1: Yêu cầu của tiêu chí là: Thư viện của trường đại học có đầy đủ sách, giáo trình, tài liệu tham khảo tiếng Việt và tiếng nước ngoài đáp ứng yêu cầu sử dụng của cán bộ, giảng viên và người học; có thư viện điện tử được nối mạng, phục vụ dạy học, học và nghiên cứu khoa học có hiệu quả. 9/17 cơ sở giáo dục chưa đạt Tiêu chí này. Các lý do Tiêu chí chưa đạt là:

- Cơ sở giáo dục thiếu giáo trình, sách tham khảo bằng tiếng Việt, tiếng nước ngoài phục vụ giảng dạy, nghiên cứu khoa học và học tập. Rất nhiều học liệu quá cũ. Cơ sở giáo dục chưa đầu tư thích đáng cho công tác giáo trình học liệu; chưa thực hiện đầy đủ quy định của Bộ GD\&ĐT về công tác giáo trình.

- Việc kết nối với thư viên điện tử trong và ngoài nước còn yếu, dung lượng đường truyền không cao nên khó khăn trong tra cứu, tìm kiếm tài liệu. Hệ thống tin học phục vụ tra cứu thư mục còn yếu, không theo dõi được số người truy cập.

- Người học ít sử dụng thư viện và thư viện điện tử, kỹ năng tra cứu yếu. Thư viện không lấy ý kiến về sự hài lòng của người sử dụng.

Tiêu chí 9.5: Tiêu chí này yêu cầu nhà trường có đủ diện tích lớp học theo quy định cho việc dạy và học; có ký túc xá cho người học, đảm bảo đủ diện tích nhà ở và cho các hoạt động văn hóa, nghệ thuật, thể dục thể thao theo quy định. 6/17 cơ sở giáo dục không đạt tiêu chí này với các lý do Tiêu chí chưa đạt là:

- Có đến 5/17 cơ sở giáo dục ngoài công lập có thời gian hoạt động hơn 20 năm nhưng vẫn phải đi thuê có sở đào tạo $100 \%$.

- Kinh phí đầu tư cho cơ sở vật chất của cơ sở giáo dục ngoài công lập đều phụ thuộc vào Chủ đầu tư hay cổ đông góp vốn. Chủ đầu tư hay cổ đông góp vốn không sẵn sàng chi tiền đầu tư quá lớn cho cơ sở vật chất mà thời gian thu hồi vốn chậm. Nếu trường không tuyển sinh được thì họ có thể đầu tư cơ sở vật chất, nghiên cứu khoa học, đào tạo đội ngũ giảng viên hay không? Trong khi đó, xu hướng chung cân bằng đang chuyển dịch theo hướng cung vượt cầu giáo dục đại học.

Tiêu chí 9.7: Tiêu chí này yêu cầu nhà trường có đủ diện tích sử dụng đất theo quy định của tiêu chuẩn TCVN 3981-85. Diện tích mặt bằng tổng thể đạt mức tối thiểu theo quy định. Có tới 13/17 cơ sở giáo dục ngoài công lập chưa đạt tiêu chí này, lý do tiêu chí này chưa đạt là:

- Cơ sở giáo dục chưa đủ diện tích tại trụ sở chính và diện tích mặt bằng xây dựng tổng thể không đủ theo quy định.

- Một số cơ sở giáo dục được cấp đất xây dựng trường nhưng lại chưa đủ vốn để giải phóng mặt bằng, đầu tư xây dựng. 


\subsection{Tiêu chuẩn 10: Về tài chính và quản trị tài chính}

Tiêu chuẩn này đòi hỏi cơ sở giáo dục có kế hoạch, giải pháp tạo ra nguồn thu hợp pháp, phân bố và sử dụng nguồn tài chính một cách minh bạch hiệu quả phục vụ đào tạo và nghiên cứu khoa học. Tiêu chuẩn này gồm 3 tiêu chí. Tiêu chí 10.1 về nguồn thu chỉ có 1 trường và Tiêu chí 10.2 về quản lý tài chính không có trường nào không đạt. Điều này có lý do vì tất cả các trường tư đều phải tự chủ tài chính hoàn toàn và không nhận bất kỳ kinh phí nào từ Nhà nước. Hệ thống kế toán, kiểm toán và kiểm soát làm việc hiệu quả và chặt chẽ theo mô hình quản lý tài chính doanh nghiệp. Riêng Tiêu chí 10.3 có tới $9 / 17$ cơ sở giáo dục chưa đạt. Tiêu chí 10.3 yêu cầu cơ sở giáo dục phân bổ, sử dụng tài chính hợp lý, minh bạch và hiệu quả cho các bộ phận và các hoạt động của cơ sở giáo dục. Lý do Tiêu chí này chưa đạt là: Phân bổ kinh phí chưa hợp lý, trong đó chi cho nghiên cứu khoa học của cán bộ, giảng viên và cho người học còn thấp hơn nhiều so với quy định, chi đầu tư cho thư viện, hệ thống công nghệ thông tin còn thấp; chi cho hoạt động hợp tác quốc tế chưa hợp lý. Kế hoạch công tác chưa đi kèm kế hoạch tài chính.

\section{Nhận xét chung}

3.1. Thông qua phân tích kết quả kiểm định của 17 trường đại học ngoài công lập và từ kết quả của 115 mẫu đối chiếu kết quả kiểm định chất lượng của 100 trường đại học công lập và 17 trường đại học ngoài công lập chúng ta có thể hình dung được một bức tranh khá toàn diện và tương đối đầy đủ về các tồn tại, hạn chế của hệ thống các cơ sở giáo dục ngoài công lập.

3.2. Công tác đảm bảo chất lượng, kiểm định và công nhận chất lượng giáo dục theo bộ tiêu chuẩn của Việt Nam lần đầu tiên mới được thực hiện (bao gồm 10 tiêu chuẩn, 61 tiêu chí). Hầu hết các cơ sở giáo dục được kiểm định lần này mới trải qua lần đầu của việc kiểm định. Do vậy, công tác kiểm định trong thời gian qua mới là sự khởi đầu làm quen với văn hóa kiểm định, làm quen với giải trình trước xã hội.

3.3. Việc kiểm định giúp cho các trường nhìn nhận về mình rõ ràng hơn theo một khung khổ (tuy chưa phải là tối ưu) hợp lý; giúp cho các trường có cơ sở thực tiễn để xây dựng chiến lược phát triển và đổi mới công tác quản trị của Nhà trường.

3.4. Tuy rằng kết quả kiểm định của 17 trường ngoài công lập còn thấp nhưng đã thể hiện được những cố gắng rất đáng ghi nhận của khối các trường này trong việc xây dựng hệ thống quản trị Nhà trường đáp ứng các yêu cầu

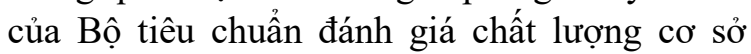
giáo dục.

Những tồn tại hạn chế đối với mỗi trường là khác nhau, có những hạn chế có thể khắc phục được ngay nhưng cũng có những hạn chế phải thực hiện năm này qua năm khác, thậm chí thế hệ này qua thế hệ khác, không chỉ là công việc của Hội đồng quản trị, của Ban giám hiệu mà của cả đội ngũ đông đảo cán bộ, giảng viên, nhân viên và sinh viên. Những thành tựu ban đầu là rất quan trọng.

\section{Lò̀i cảm ơn}

Bài viết được tài trợ của đề tài: Đề xuất các giải pháp phát triển bền vững các Trường đại học ngoài công lập ở Việt Nam.

\section{Tài liệu tham khảo}

[1] Cổng thông tin điện tử của Trung tâm Kiểm định chất lượng giáo dục, Hiệp hội các trường Đại học và Cao đẳng Việt Nam. http://cea-avuc.edu.vn.

[2] Cổng thông tin điện tử của Trung tâm Kiểm định chất lượng giáo dục, Đại học Quốc gia Hà Nội. http://cea.vnu.edu.vn.

[3] Cổng thông tin điện tử của Trung tâm Kiểm định chất lượng giáo dục, Đại học Quốc gia Hà Nội. http://cea.vnuhcm.edu.vn.

[4] Cổng thông tin điện tử của Trung tâm Kiểm định chất lượng giáo dục, Đại học Đà Nẵng. http://cea.udn.vn/. 
[5] 20 Báo cáo đánh giá ngoài, 117 Nghị quyết của các Hội đồng Kiểm định chất lượng giáo dục.

[6] Báo cáo tự đánh giá Trường Đại học Công nghệ Sài Gòn.http://www.stu.edu.vn/vi/1/14071/truongdai-hoc-cong-nghe-sai-gon-hoan-thanh-bao-caotu-danh-gia-co-so-giao-duc-nam-2017.html.

[7] Báo cáo tự đánh giá Trường Đại học Đông Á. http://dbcl.donga.edu.vn/thong-tin-ct/du-thao-bao- cao-tu-danh-gia-co-so-giao-duc-truong-dai-hocdong-a-(lan-1)-13741.

[8] Báo cáo tự đánh giá Trường Đại học Tây Đô. http://tdu.edu.vn/cong-khai/c\%C3\%B4ng-khaigi\%C3\%A1o-d\%E1\%BB\%A5c/1572-

vb_kiem_dinh_gd.html.

[9] Báo cáo tự đánh giá Trường Đại học Việt Bắc. http://www.vietbac.edu.vn/bao-cao-tu-danh-giadt347.html. 